AIR WAR COLLEGE

AIR UNIVERSITY

\title{
ROOT CAUSE ANALYSIS OF SEXUAL ASSAULT: SHIFTING FROM EARLY DETECTION TO A VACCINE
}

\author{
by \\ Christine F.L. Holliday, Lt Col, USAFR \\ A Research Report Submitted to the Faculty \\ In Partial Fulfillment of the Graduation Requirements \\ Advisor: Dr. Christopher M. Hemmer
}

17 February 2015 


\section{Report Documentation Page}

Public reporting burden for the collection of information is estimated to average 1 hour per response, including the time for reviewing instructions, searching existing data sources, gathering and maintaining the data needed, and completing and reviewing the collection of information. Send comments regarding this burden estimate or any other aspect of this collection of information, including suggestions for reducing this burden, to Washington Headquarters Services, Directorate for Information Operations and Reports, 1215 Jefferson Davis Highway, Suite 1204, Arlington VA 22202-4302. Respondents should be aware that notwithstanding any other provision of law, no person shall be subject to a penalty for failing to comply with a collection of information if it does not display a currently valid OMB control number.

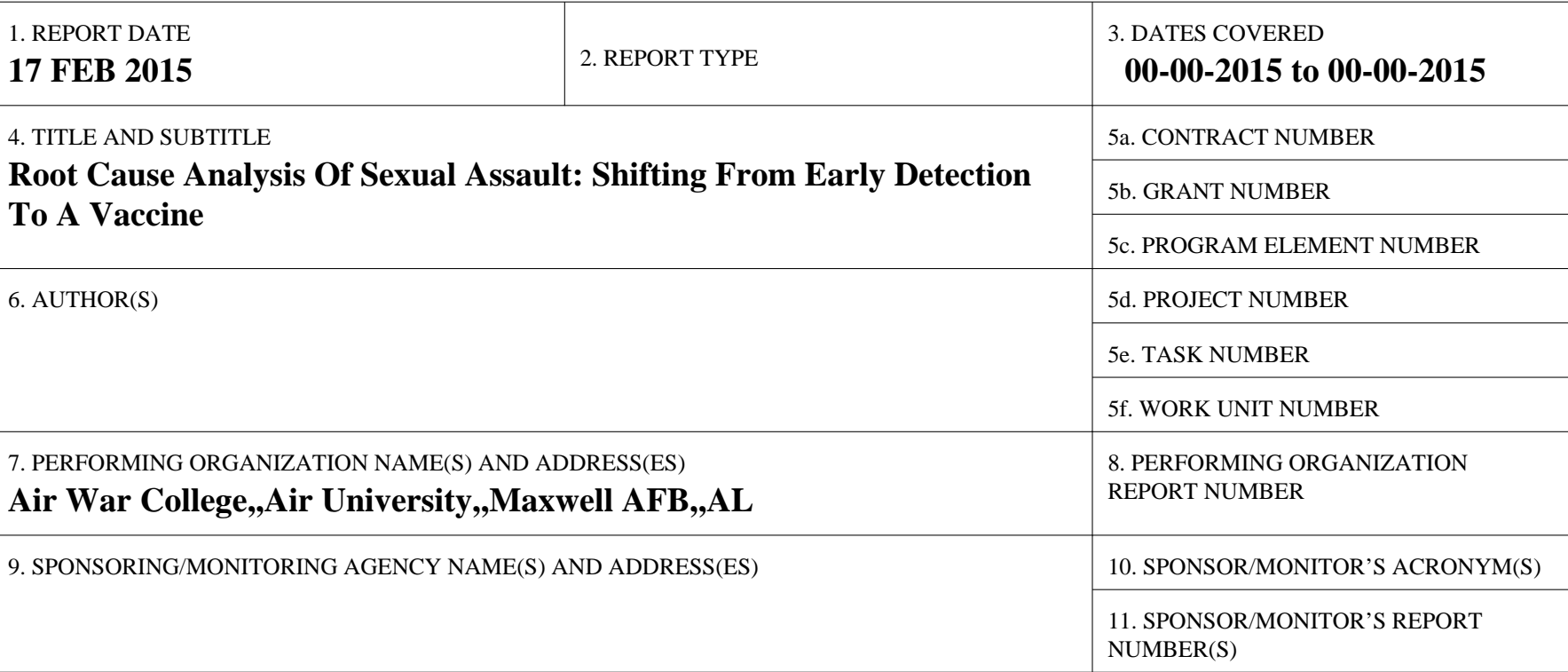

12. DISTRIBUTION/AVAILABILITY STATEMENT

Approved for public release; distribution unlimited

13. SUPPLEMENTARY NOTES

14. ABSTRACT

With good intention, the Chief of Staff of the Air Force labeled sexual assault as a cancer; however, it is precisely this thinking that hinders a successful prevention strategy, focusing on early detection of the disease rather than a vaccine. Unarguably, the Air Force needs to remedy the cancer with detection, reporting, and treatment when sexual assault does occur. But current AF prevention is philosophically flawed. Annual education efforts on sexual assault, by-stander training, and predator identification are similar to annual physical exams checking for lumps and early detection of cancer. The AF must change its philosophy from a solely informational strategy to individual skill development. Just as root sources for cancer are mitigated by not smoking, minimal sun exposure, adopting healthy eating habits and alcohol use, sexual assault is mitigated by developing skills in effective communication, relationships, love, and esteem. This paper argues the AF desperately needs to transition from providing facts and narratives to a robust developmental program???administering a vaccine aimed specifically at the roots of sexual assault. It investigates these root causes and offers an explanation on how they connect to sexual assault. Finally, the author recommends an infusion of ???life skills??? into its Airmen. If DoD and the Air Force continue to promote the goal of eliminating sexual assault from its ranks, it must invest in its members with a vigorous program like Skills for Life; otherwise it is an unrealistic goal and the leaderships??? stance is simply rhetoric.

15. SUBJECT TERMS

16. SECURITY CLASSIFICATION OF:

a. REPORT unclassified b. ABSTRACT unclassified c. THIS PAGE unclassified
17. LIMITATION OF ABSTRACT

Same as Report (SAR)
18. NUMBER 19a. NAME OF OF PAGES RESPONSIBLE PERSON 
Standard Form 298 (Rev. 8-98) Prescribed by ANSI Std Z39-18 


\section{DISCLAIMER}

The views expressed in this academic research paper are those of the author and do not reflect the official policy or position of the US government, the Department of Defense, or Air University. In accordance with Air Force Instruction 51-303, it is not copyrighted, but is the property of the United States government.

Additionally, the author recognizes there are a larger number of male victims of unwanted sexual contact than women in our military. However, due to percentages reporting in most studies, the literature is slanted to use male nomenclature when referring to the attacker and female for victims. For ease of quoting sources and transition to the author's writing, this nomenclature will remain consistent. However, the author does so with regret that male victims and the large majority of male non-rapists may be offended.

Finally, though the author supports a theory that potential victims sometimes put themselves in safety-averse situations, there is absolutely no intention to convey that victims are to blame for their assault. 


\section{Biography}

Lieutenant Colonel Christine Holliday earned her Active Duty commission in 1991 from the United States Air Force Academy, majoring in Applied Mathematics. She holds two MS degrees, Statistics from the University of Texas in San Antonio, 1994, and Military Operational Art \& Science from Air University at Maxwell AFB, 2008. She is a senior pilot with almost 2000 hours in the C-141B and has participated operationally in contingency Operations SOUTHERN WATCH, JOINT ENDEAVOR, PROVIDE PROMISE, UPHOLD DEMOCRACY, ASSURED RESPONSE and DEEP FREEZE. She acquired her Lead Pilot, Mission Commander, Air Refueling, Airdrop, and Aircraft Commander qualifications while assigned to 15th and 16th Airlift Squadrons, Charleston AFB, SC.

Upon transitioning to the US Air Force Reserves, Lieutenant Colonel Holliday chaired the Academic Support and International Security Studies departments for the Commandant of Squadron Officer College, Maxwell AFB. She graduated top 15\% of her class at Air Command and Staff College. She returned to her alma mater, USAFA, as an Assistant Professor in the Department of Mathematical Sciences, where she taught Calculus and Statistics, course directed, and advised the Dean of the Faculty as Director of Reserve Affairs. She then served as Deputy Group Commander, responsible for the command and control of 1,100 cadets, 10 officers, 21 NCOs and 1 civilian, Reserve Advisor to the Commandant and, finally, as the Deputy Director of Staff to the Superintendent. Lt Col Holliday is currently assigned to the Air War College, Air University, Maxwell AFB, AL.

Additionally, she is a Delta Air Lines pilot with over 2000 flight hours in the MD-90, MD-88 and B-727. 


\begin{abstract}
With good intention, the Chief of Staff of the Air Force labeled sexual assault as a cancer; however, it is precisely this thinking that hinders a successful prevention strategy, focusing on early detection of the disease rather than a vaccine. Unarguably, the Air Force needs to remedy the cancer with detection, reporting, and treatment when sexual assault does occur. But current AF prevention is philosophically flawed. Annual education efforts on sexual assault, by-stander training, and predator identification are similar to annual physical exams checking for lumps and early detection of cancer. The AF must change its philosophy from a solely informational strategy to individual skill development. Just as root sources for cancer are mitigated by not smoking, minimal sun exposure, adopting healthy eating habits and alcohol use, sexual assault is mitigated by developing skills in effective communication, relationships, love, and esteem. This paper argues the AF desperately needs to transition from providing facts and narratives to a robust developmental program-administering a vaccine aimed specifically at the roots of sexual assault. It investigates these root causes and offers an explanation on how they connect to sexual assault. Finally, the author recommends an infusion of "life skills" into its Airmen. If DoD and the Air Force continue to promote the goal of eliminating sexual assault from its ranks, it must invest in its members with a vigorous program like Skills for Life; otherwise it is an unrealistic goal and the leaderships’ stance is simply rhetoric.
\end{abstract}



"Nothing saddens me more than knowing this cancer exists in our ranks..."

Gen Mark Welsh, Chief of Staff of the US Air Force

to Senate Armed Services Committee

4 Jun 2013

\section{Introduction}

With good intention, the Air Force Chief of Staff labeled sexual assault as cancer; however, it is precisely this thinking that hinders a successful prevention strategy, focusing on early detection of the disease rather than a vaccine. Unarguably, the Air Force(AF) needs to remedy the cancer with detection, reporting, and treatment when sexual assault does occur. But current AF prevention is philosophically flawed. Annual education efforts on sexual assault, bystander training, and predator identification are similar to annual physical exams checking for lumps and early detection of cancer. The AF must change its philosophy from a solely informational strategy to individual skill development. Just as root sources for cancer are mitigated by not smoking, minimal sun exposure, adopting healthy eating habits and alcohol use, sexual assault is mitigated by developing skills in effective communication, relationships, love, and esteem. Infusing "life skills" into its Airmen, identifying and focusing on root issues of the cancer rather than early detection of the cancer itself, will give the AF a vaccine-a more viable prevention strategy.

\section{Early Detection Versus A Vaccine}

Sexual assault is a military, national and global problem. ${ }^{1}$ Despite widespread attempts, there is no known solution; college campuses make considerable efforts but sexual assault rates have not declined over the last five decades. ${ }^{2}$ A yearlong immersion study of a university female 
dorm concludes, regardless of $1^{\text {st }}$-year sexual assault orientations, frequent sexuality workshops, student volunteers conducting rape awareness, and annual Take Back the Night marches, ${ }^{3}$ "we do not have a complete explanation of the problem..”4 Similarly, a recent Department of Defense(DoD) report to the President celebrates reduction of unwanted sexual contact and increases in victim reporting, nonetheless concluding much work is still to be done ${ }^{5}-$ exemplified by 2014 AF victim reports for males and females, 191 and 885 respectively, suggesting a reality much closer to roughly 3,000 assaults annually. ${ }^{6}$ Lack of weighty improvement within college communities and the AF, despite significant investments and resources, suggests current prevention programs are not hitting the mark. Acknowledging these efforts for what they are, minimally effective education campaigns, allows for a transition to what prevention needs to become—a development program.

Admittedly, an information strategy can be helpful in educating an audience; however, it is nominal in changing a culture or instilling an internal ethic within a designated population. Bloom's education taxonomy clearly establishes the difference between first-level receiving information and fifth-level internalizing ${ }^{7}$ in achieving such affective goals-likewise there are numerous sources documenting the difficulty of changing a culture. The AF's Center for Character and Leadership Development(CCLD) painstakingly documents its research justifying the philosophy behind its 4-year developmental program to instill Core Values and the Academy's Honor Code. ${ }^{8}$ Unfortunately, knowledge and awareness is the only thing DoD's current sexual assault prevention program attempts. Its primary prevention plan, detailing all efforts prior to any sexual violence to prevent initial perpetration, ${ }^{9}$ requires all service members once-a-year training regardless of rank or specialty. ${ }^{10} 2014$ AF Sexual Assault Prevention Response(SAPR) annual training involved: ${ }^{11}$ 
- 45-60 minute Wing Commander call with mandatory videos/slides provided by HQ AF

- 3 hour small group discussion, mandated intra-unit; 25 per facilitator/50 per 2 facilitators o Volunteer facilitators need 8 hours of training to execute scripted dialogue/engagement - Team Building exercise (optional)

Commanders are labeled the "center of gravity" for prevention success, responsible for unit climate by setting "an example of appropriate behavior, to be proactive in identifying and rooting out inappropriate behaviors, and to mentor and educate unit members through targeted messaging on sexual assault prevention.” ${ }^{12}$ The DoD report concludes recent enhancements "increase the likelihood of a more informed military,"13 alluding to a solely knowledge-based strategy.

Similarly, projected 2015 SAPR training shows promising modifications but still an information-type effort. "To increase learning and change behavior, training and education must be repeated frequently;" however, behavior change does not come from education and training alone, it requires a development process with experiential outcomes. ${ }^{14}$ A notable improvement requires smaller groups “to generate continuous dialogue.” Unfortunately, the curricula selection still largely focus on providing information—with no promise of developing new skills.

DoD prevention efforts are enhanced during accession training, a logical requirement since $43 \%$ of military members ${ }^{15}$ are the target population of 16 to $24,{ }^{16}$ and the total force is getting younger. ${ }^{17}$ However, it appears to only acknowledge the new population rather than seize an opportunity to affect its target population. DoDI mandates only one addition during accession, "to demonstrate the entire cycle of prevention, reporting, response, and accountability procedures. . .to clarify the nature of sexual assault in the military environment." ${ }^{\text {"18 }}$ Again, this clarification only educates its newcomers in early detection, rather than developing Airmen's skills towards prevention. 
The latest prevention strategy, bystander training, answers concerns of alienating men during sexual assault discussions—stressing everyone has a role to play in ending sexual violence. ${ }^{19}$ A social messaging system utilizing posters, depicting military members vowing to stop sexual assault, removes servicemen from the all perpetrators label and servicewomen from all victims. ${ }^{20}$ More importantly, the posters establish a connection "essential for the target audience to recognize themselves or people like them or their friends in the images.”21 Again, this is still an informational message, but this connection hints at deeper requirements for sexual assault prevention.

Finally, a 2014 study of the AF SAPR program, by the Scientific Advisory Board $(\mathrm{SAB}),{ }^{22}$ found several areas for improvement in the prevention arena. Recommendations include a more consistent delivery system with more localized programs "tailored for mission and demographics." ${ }^{23}$ Another significant recommendation introduces peer influencers and counselors - once again recognizing a connection needed for a successful prevention strategy. Unfortunately, recommendations regarding program content continue to focus on information and messaging for early detection, rather than developing skills aimed at any root causes.

Root causes of sexual assault are brought into the military, just as they are brought into

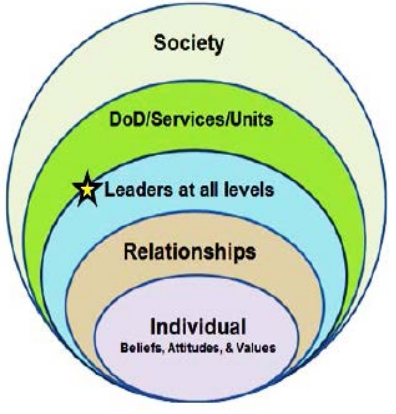

Figure 1: DoD Social-Ecological Model college campuses, from diverse environmental and familial experiences each service-member embodies. DoD’s Social-Ecological model, Figure 1, shows an awareness of the complex network, ${ }^{24}$ but its prevention program does not attempt to resolve what the model so plainly depicts—-the intricacy of individuals meeting their own needs through personal and professional relationships, while conforming to DoD and societal expectations. 
DoD does not promote or condone sexual assault; however, many values and norms in society, exacerbated by a male-dominated organization, create a fertile environment. Children learn rules early from parents, then "moral perceptions of right and wrong and beliefs about sex roles are brought by television and videos, popular songs, children's books, and jokes,"25 generally sources of negative learning. ${ }^{26}$ Parents tell little girls they should be flattered by a boy's aggressive behavior because it means he likes her; "this prepares both boys and girls to confuse love with abuse and socializes girls to feel helpless."27 2014 TV commercials show children/teens having confidence to take what they want (a kiss without permission) and declaring, "victory is yours." ${ }^{28}$ Entering the male-dominated military intensifies these accepted norms. "The military does not have a rape culture, it has a hyper-masculine culture like few others. . .and that culture may propagate sexual assault at higher rates than society at large, among other things." ${ }^{29}$ It is impossible to reprogram infinite subconscious messages via an annual down-day or computer-based training; constant re-messaging, inculcating a culture of dignity and respect, must be developed and modeled from the top down, all ages, both men and women. ${ }^{30}$ Additionally, young members entering the military suddenly have a new atmosphere; "alcohol accessibility in combination with newfound independence, peer pressure, close quarters, integration of units, limits on privacy, and new relationships could [also] contribute to increased risk of sexual assault.”31 The military's inability to purposefully acknowledge these issues and teach useful skills to maneuver successfully, denigrates any prevention strategy.

The lack of actively connecting these issues to the prevention program creates a vacuum between education efforts and Airmen's actions; missing an opportunity for skill development to enable prevention. For example, teaching emphasis on obtaining verbal consent $t^{32}$ does not introduce appropriate ways to go about this, failing to appreciate communication differences 
between men and women ${ }^{33}$ or the complexities of widely accepted nonverbal ${ }^{34}$ communication. This verbal consent focus pushes assaulters to utilize exhausting arguments or manipulation ${ }^{35}$ on new acquaintances and lasting relationships. ${ }^{36}$ "A disturbingly large number of [college] men identified themselves to be at risk to perpetrate sexual aggression ... [via] arguments or pressure to engage in sex play (35.1\%), [and] to engage in sexual intercourse (12.1\%). ${ }^{37}$ Another example is the information campaign detailing characteristics of predators and victims. ${ }^{38}$ Though factual, it does not allow for skill development in how to handle certain social situations, dating scenarios or expectations ${ }^{39}$ where these characteristics are encountered. "The American dating system is a major contributing factor placing men and women in highly socialized but differing expectations regarding sex role behavior in ambiguous situations with maximum privacy." ${ }^{40}$ The AF must accept that merely providing information to its Airmen does not enable them with skills to make better choices and change the current environment. Finally, there is little education on what sexual assault looks like in lasting relationships ${ }^{41}$ or, conversely, what is a healthy relationship experience. Sexual assault is largely connected to communications and relationships - instead of defining what not to do and arming Airmen with facts, it is time to identify models of success and create ways to improve these skill sets.

This vaccine approaches sexual assault from a different angle—accepting it as a symptom of other foundational issues. All AF efforts, up to this point, attempt to detect symptoms that, by definition, will never inoculate a population. Airmen must be transformed prior to any sexual assault symptoms, particularly the newest Airmen, by internalizing a culture of dignity and respect. This transformation can only occur through development, "both a process and an outcome experienced by an individual" ${ }^{42}$ —AF and SAPR leadership must adopt this philosophy. A program, stimulating Airmen's development and personal growth, encompassing 
root causes of sexual assault, will expose foundational issues for each individual—-the only way prevention can be realized.

Sexual assault "betrays the very trust on which our profession is founded. . .we can and must do more. . .we must be open to every idea and option to accelerate meaningful, institutional change."

Army Gen. Martin Dempsey, Chairman of the Joint Chiefs

to Senate Armed Services Committee

4 Jun 2013

\section{Exploring Root Causes}

Identifying root causes for sexual assault is no easier than identifying them for cancer, and certainly cannot be an all-inclusive list. However, we must be open to look beyond currently accepted strategies. A different approach, going back to basics, is in order; deconstructing basic human psychology reveals common threads driving human motivation. Treating sexual assault as a misguided symptom of some basic motivations highlights traits that, with nurturing and skill development, can reduce the likelihood for perpetration and victimization-a viable vaccine approach. Human connection is an attribute to SAPR's movement to small groups and the bystander-messaging program; however, the reasoning behind the importance of connection is missed. Human motivation for love, belonging and esteem, originally defined by Dr. Abraham H. Maslow, is the driver for this connection and symptomatic in parental, friend, dating, marital and professional relationships. A popular book on “dating rituals” is an excellent modern reference to the desperate desires yet misplaced actions in fulfilling basic human motivationsultimately requiring an appreciation for Dr. Maslow’s theory.

\section{The Game}

The Game is a non-fiction account of a man with self-admitted low esteem in talking/meeting/dating women and, ultimately, attaining the goal of sex. This book, referred to 
by law enforcement as a rapist’s "how-to," gives rare insight into a psyche among immature men and women regarding sex and relationships. It centers on developing the art of getting sex with the author's underlying assumption it will bring happiness. He gains esteem in mastering the art, belonging through the gang-like group pursuing the art and even love via a close male friendship. "Sex [isn’t] about getting your rocks off; it [is] about being accepted." ${ }^{33}$ However, there are moments in the book where he reveals sex is not giving him what he thought he wanted. When his best friend breaks down after a relationship failure, the author sheds sympathetic tears and has an epiphany, "After two years in the seduction community, I still didn’t have a girlfriend, but for some reason I had bonded with this [guy]. Perhaps it was really shared emotion and experience that creates relationships, not seven hours of routines followed by two hours of sex." ${ }^{44}$ He discovers he is no more adept at relationships or capable of love. He laments "sincerity, genuineness, trust, and connection" are important to women in maintaining a relationship but "all the techniques effective in beginning a relationship violate" those very principles. ${ }^{45}$ Thankfully, he ends the book proclaiming "we were all searching outside of ourselves for our missing pieces, and we were looking in the wrong direction. . .to win the game was to leave it." ${ }^{46}$

The concept of men and women "searching outside" is the core issue and fundamental problem with sexual assault prevention to-date. The Game highlights less focused phenomena of target age males' interpretation on how to best attain internal needs that have nothing to do with sex. This is not a phenomenon shared by males alone, females also have deep-seated psychological needs driving them to seek external satiation. Adding to the complexity, women seek love, belonging and esteem in different ways. "Men derived status from securing sex, while women derived status from getting attention. These agendas are both complementary and 
adversarial." ${ }^{47}$ It is both our young males and females complete misunderstanding of their root cause needs that gets them into potential sexual assault situations—intentionally and unintentionally. A successful prevention strategy requires reflection on basic motivations and psychology behind these agendas.

\section{Motivation Theory}

Abraham H. Maslow is renowned in the psychology community for his motivation

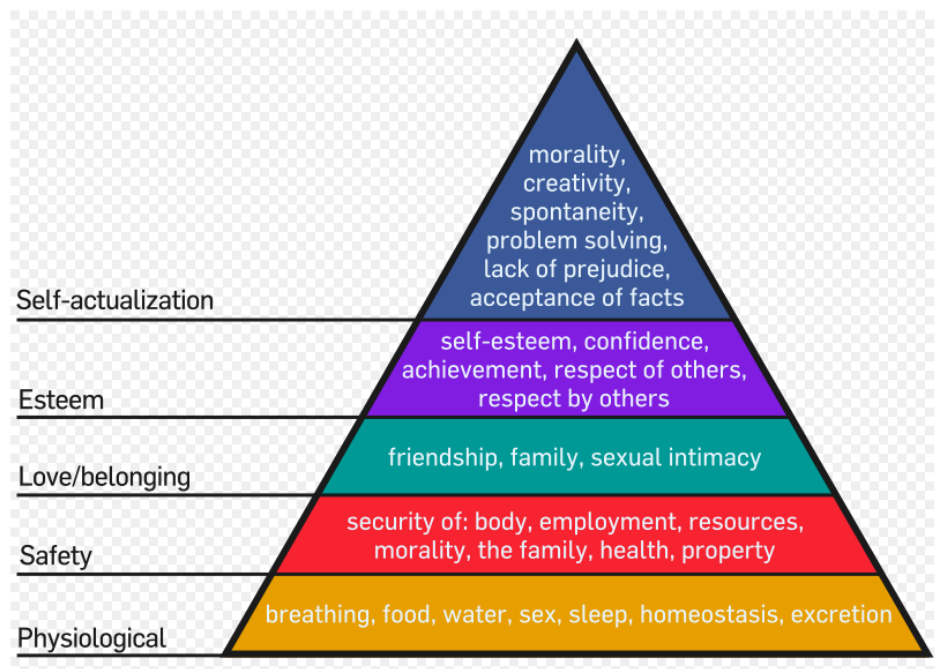

Figure 2: Maslow's Hierarchy of Needs theory, commonly known as the

Hierarchy of Needs, Figure $2 .{ }^{48}$ His well-accepted premise is every human motivation starts at the triangle base and as a need is met the next level becomes the person's focus. Though generally a hierarchy where basic needs must be acquired before higher needs are

pursued, he acknowledges crossing over between levels can sometimes happen when a higher level becomes all-consuming to the individual. For example, an abused child will give up safety by still clinging desperately to its physically abusive parent out of the stronger need for love and belonging at that moment. Similarly, we can connect this to the barriers of sexual assault reporting ${ }^{49}$ where victims are more in need of acceptance, love, and belonging than righting the safety wrong. Additionally, he acknowledges multiple motivations drive the pursuit of certain needs. 
Maslow discusses the complexities of human sexuality, separating the physiological need of procreation for species survival from sexual desire, which may serve several underlying purposes:

"In one individual sexual desire may actually mean the desire to assure himself of his masculinity. It may in other individuals represent fundamentally a desire to impress, or a desire for closeness, friendliness, for safety, for love, or for any combination of these. Consciously the sexual desire in all these individuals may have the same content, and probably all of them would make the mistake of thinking that they seek only sexual gratification. But we now know that this is not correct, that it is useful in understanding these individuals to deal with what the sexual desire and behavior represent fundamentally rather than what the individual consciously thinks they represent." ${ }^{, 0}$

Further, Maslow identifies when two levels are gratified, greater value is usually placed on the higher-level need than the lower. ${ }^{51}$ Thus, people will sacrifice much more to attain the higher need at a cost or depravation to an already regularly satisfied lower need.

Maslow does not specifically address sexual assault or the need for power or dominance. However, his study of sexual deprivation possibly causing aggressive behavior is noteworthy. "Clinical work with nonneurotic people gives the clear answer that sexual deprivation becomes pathogenic in a severe sense only when it is felt by the individual to represent rejection by the opposite sex, inferiority, lack of worth, lack of respect, isolation, or other thwarting of basic needs. "52 In fact, he discovers those individuals who do not attach sexual deprivation with these negative connotations bear the deficiency with relative ease.

Maslow's third and fourth levels illuminate the problem of assimilating new Airmen into the AF and the challenge of sexual assault prevention. With food and safety generally fulfilled for AF recruits, ${ }^{53}$ love-needs become a primary focus — the idea of giving and receiving affection. A person will make great efforts for a place in the group or family, ${ }^{54}$ precisely why military basic training is highly effective; breaking members down and building them back up 
into a cohesive team, playing completely on Maslow's third level. Unfortunately, there are other side effects to this model. We have young adults, usually their first time away from home and friends (their only source of "love" while the military unit may provide "belonging"), some of which have never experienced dating, immature regarding relationships and sexuality, and raging hormones. Maslow theorizes, and admits with very little scientific evidence, society's "unsatisfied hunger for contact, intimacy, and belongingness" and "widespread feelings of alienation, strangeness, and loneliness. . .have been worsened by increasing mobility, the breakdown of traditional groupings, the scattering of families, the generation gap, and steady urbanization., ${ }^{55}$ The military lifestyle exacerbates the problems these young Airmen already possess from their own background.

Maslow's fourth level, esteem, is broken into two sets, the first being the self's pursuit of strength, competence, and freedom. The second, and more important to this discussion, is the pursuit of external respect like "reputation. . . status. . . dominance. . .attention." ${ }^{\text {"66 }}$ Satisfying this need leads to self-confidence and self-worth as a contributor to the world; oppositely, lacking in this need leads to "feelings of inferiority, of weakness, and of helplessness." ${ }^{\text {"57 }}$ The military concept for new recruits denies attainment of esteem initially to force team building. Though team, and future individual, successes are intended to rebuild a recruit's confidence, the AF does not know enough about the individual's background and previous levels of esteem. Without careful and concentrated efforts to ensure an individual's personal level of esteem is rebuilt, there can be unintended consequences.

The confounding factors of Maslow's theory, the numerous fundamental representations of sex to men and women, and the lack of self-actualization of the target population ${ }^{58}$ creates the recipe for sexual assault disaster we are witnessing at college campuses and the military. Target 
population men and women are struggling with identity and now, separated from their immediate sources of love and esteem, are desperate for status and belonging. Their inability to separate conscious reasons for pursuing sex (or attention) from underlying subconscious representations of sex (or attention) further confuses the issue when the physical need is satisfied but the subconscious representations are not. Additionally, pursuit of the higher level of love or esteem over safety, when safety is generally satisfied, will push men to sacrifice the possibility of a rape charge (safety) over the pursuit of the higher level need of whatever sex represents for them (love, status, power, you name it). A study of pathological physical/sexual abusers reveals, "they feel a sensation inside they call love. . .it is the only kind of feeling toward a female partner they have ever had, so they have no way of knowing it isn't love. . .he may be capable of feeling genuine love, but first he will have to dramatically reorient his outlook in order to separate abusive and possessive desires from true caring."59 Similarly, women will put themselves in safety-averse situations in pursuit of their higher-level needs (love, esteem, again, you name it). And to top it all off, because of both sexes' lack of identity and autonomy, this target population may not be able to consciously decide to make different choices even if this was all explained to them, sans alcohol! However, understanding this paradox does not mean we should give up; we must be creative in finding ways to attack these root problems through developmental education and teaching effective life skills.

\section{Inoculating Airmen}

The AF lacks a program helping new Airmen assimilate different life experiences while adapting to Core Values and a culture of dignity and respect. A program investing in Airmen's "life skills” will be better received, better internalized and create better self-actualization. 
Additionally, this concept allows self, peer or facilitator identification of individuals needing more personalized help in any number of areas. Realistically, a distinctly new program is fiscally unthinkable in today's receding budgets; though, beyond the scope of this paper, costs in AF legal expenses, Article 138s and Court Martials, in addition to victim long-term treatment, ${ }^{60}$ justifies front-end investment in prevention to lower tail-end costs. Fortunately, existing assets

allow a fiscally responsible proposal supporting DoD’s "sustained commitment." 61 An expanded Comprehensive Airman Fitness $(\mathrm{CAF})^{62}$ framework with a CCLD sponsored curriculum, inculcating peer and train-the-trainer programs, is a flagship vaccine I call, Skills for Life.

\section{Skills for Life}

This vaccine should not be confused with common courses on how to survive freshman year in college. Rather, this program develops and infuses skills beneficial for all young Airmen as they mature and face life experiences—intentionally incorporating root issues from Maslow's third and fourth levels of motivation. The core concept of Skills for Life centers on establishing a non-attribution environment, with long-term small-group integrity, creating trust \& peer support through discussions and exercises to develop communication and relationship skills. First, nonattribution and safety is generated via inter-unit random selection, opposite of SAPR-mandated groups within squadrons. Members of same units have a homogenous effect inhibiting frankness on numerous levels. ${ }^{63}$ Secondly, facilitators require a discerning selection process. PhDs or licensed counselors are not what this program needs — Airmen able to connect and share real-life events are vital. Purposeful engagement is proven, especially among college-age students, in self-efficacy and engraining identity-conferring behaviors into firm and stable habits. ${ }^{64}$ Thirdly, small group size ensures individual connection; clinical group therapy recommends 8 members, 12 with two facilitators, ${ }^{65}$ or SAPR's most recent plan of 10 to $15{ }^{66}$ Fourth, long-term group 
integrity develops from shared experiences—-from long weekend immersion to consistent weekly meetings over the course of several months, semester or year-establishing a support network external to the member's unit and circle of friends or family. Sustained and meaningful relationships develop trust, “an essential ingredient to full engagement," and, ultimately, the willingness to be vulnerable. ${ }^{67}$ Finally, Skills for Life uses this approach with a curriculum focused on the aforementioned root causes for sexual assault.

There are many readily available sources providing a wealth of topics striking at the heart of the target populations' struggles within the Hierarchy of Needs. Recently, a USAFA team identifying consistent cadet issues created an initial list of Skills for Life topics, jokingly referred to as "what your parents didn’t tell you and what your friends told you wrong:" 68

\begin{tabular}{|c|c|}
\hline \multicolumn{2}{|c|}{ A Starting Point - Initial Topic Recommendations } \\
\hline Relationships & Text/Email - Effects on Relationships \\
\hline Sex/The Biology \& The Complexities & Past Major Life Events - How They Influence You Today \\
\hline Sexual Harassment/Assault & Knowing Personal Boundaries \\
\hline Suicide & Navigating a Counter Culture \\
\hline Drugs & 4 Identities of Women \\
\hline Bystander Behavior & Basic Development/Personal Identity \\
\hline Sexuality & Pornography \\
\hline Dating & STDs/Communicable Diseases \\
\hline He Said/She Said - Mars vs Venus & Predatory Behaviors \\
\hline 5 Languages of Love & Alcohol/Drinking Responsibly \\
\hline Feelings of Not Fitting In & Self-Esteem \& Its Effects on Decision-Making \\
\hline Loneliness & Depression \\
\hline
\end{tabular}

Numerous books, self-empowerment curricula and counselor recommendations support this initial list and can further refine it; I Never Knew I Had A Choice, targeting college-age men and women, recommends,

"The topics include choosing a personal style of learning; approaches to personal growth; the body; the roles that sexuality, love, intimacy, work and solitude play in our lives; the meaning of loneliness, death and loss; and the ways we choose our values and philosophies of life. . .my experience has been that active, open and personal participation in these courses can lead to expanded self-awareness and greater autonomy in living." 69 
Airmen can build self-awareness and autonomy with purposeful open dialogue in these areas, enhancing communication and relationship-building skills, while using experiential curricula. The CCLD mission, ${ }^{70}$ paralleling the AF's mission to create a culture of dignity and respect, continually cultivates and oversees a 4-year tiered development program, recognizing "cadets can receive training or education and yet never develop a deeper insight or awareness.” Thus, CCLD is well-experienced and qualified to sponsor an AF Skills for Life developmental syllabus with a calculated, tiered execution based on Airman career milestones and personal progression, summarized in Table $1 .^{71}$

\begin{tabular}{|c|c|c|c|c|c|}
\hline Teir & Audience & & Agenda & Why Now? & Time Concept \\
\hline 1 & Early Accession & Same Sex & $\begin{array}{c}\text { Biology of sex, safe sex, STDs, } \\
\text { sexual harassment \& assault, etc. }\end{array}$ & $\begin{array}{l}\text { Critical items to ensure normalization } \\
\text { in knowledge and AF expectations }\end{array}$ & $\begin{array}{l}\text { Informational } \\
\text { periods + weekly } \\
\text { small group }\end{array}$ \\
\hline 2 & $\begin{array}{l}\text { Late/Immediate Post } \\
\text { Accession }\end{array}$ & Same Sex & $\begin{array}{l}\text { Love, acceptance, esteem, } \\
\text { Ionliness, communication, } \\
\text { relationships, drugs/alcohol, etc. }\end{array}$ & $\begin{array}{l}\text { Foundational prior to lifestyle change } \\
\text { and acquiring newfound freedoms }\end{array}$ & $\begin{array}{l}3 \text { Consecutive Days } \\
\text { Immersion Course }\end{array}$ \\
\hline 3 & $\begin{array}{l}\text { Technical Training } \\
\text { Assignment }\end{array}$ & $\begin{array}{c}\text { Same sex/ } \\
\text { Coed }\end{array}$ & $\begin{array}{l}\text { Love, acceptance, esteem, } \\
\text { Ionliness, communication, } \\
\text { relationships, drugs/alcohol, etc. }\end{array}$ & $\begin{array}{c}\text { Continued foundation, establish new } \\
\text { trused peer network }\end{array}$ & $\begin{array}{l}\text { Depends on } \\
\text { training duration; } \\
\text { weekly/bi-weekly }\end{array}$ \\
\hline 4 & $\begin{array}{l}\text { First Assignment } \\
\text { peers }\end{array}$ & Coed & $\begin{array}{c}\text { all topics, tailor to local } \\
\text { base/mission issues }\end{array}$ & $\begin{array}{c}\text { Further skills, appreciate different } \\
\text { perspectives in coed peers }\end{array}$ & $\begin{array}{l}\text { 1st Yr: bi-weekly } \\
\text { OW: monthly }\end{array}$ \\
\hline 5 & All & Coed & $\begin{array}{l}\text { all topics, tailor to local } \\
\text { base/mission issues }\end{array}$ & $\begin{array}{l}\text { Maintenance, appreciate coed and } \\
\text { generational perspectives }\end{array}$ & $\begin{array}{l}\text { 1st Yr: monthly } \\
\text { OW: quarterly }\end{array}$ \\
\hline
\end{tabular}

Table 1: Tiered Execution Plan

Such an extensive program requires expert training and train-the-trainer initiatives for effectiveness and feasibility. Expanding CAF's infrastructure ${ }^{72}$ is the first step; assign Master Resiliency Trainers(MRT) ${ }^{73}$ as gatekeepers of local Skills for Life implementation, executing in both facilitator and train-the-trainer roles. Though unit-specific, MRTs will coordinate with their Community Support Coordinator ${ }^{74}$ to build inter-unit small groups. MRT selection must demand communication, compassion and feedback skills—it is not enough to simply volunteer or perform well, and counseling or accreditation does not guarantee the ability to connect to people. Once selected, MRTs need self-actualization and purposeful life training offered in the 
private sector. ${ }^{75}$ Companies like Pathways to Successful Living Seminars, ${ }^{76}$ with considerable experience and data in this arena, are already adapting to military needs; thus, they are a valuable resource to establish initial Skills for Life training with an enduring train-the-trainer program. ${ }^{77}$

Next, the CAF will need additional support drawn from the target population. Resilience Training Assistants(RTAs) must be close in age to the target population, modeling the USAFA Personal Ethics and Education Representative(PEER) program; ${ }^{78}$ if young Airmen cannot connect with facilitators and small-group peers, Skills for Life will not reach its full potential. Additionally, MRTs and RTAs will identify Airmen with social capital to lead and correct their peers, the most reliable way to mitigate sexual assault.

"Egalitarianism will not work to solve this problem, because while we are all in this together, the problem is remarkably lopsided to affect our youngest service members. Leaders should be held accountable for setting the conditions for their subordinates to lead each other and change their culture."79

Only through target population RTAs/PEERs, Skills for Life peer-networks, and self-selected wingmen, combined with unit MRT, supervisor and mentor availability, sharing day-to-day operations and/or social networks, can Airmen experience prevention.

Though sexual assault prevention is the ultimate goal, there are additional positive sideeffects realized throughout the Skills for Life program; peer support networks, identification of similar life struggles, normalization and identifying popular peers. Learning to trust and communicate on difficult topics reinforces the wingman concept, establishing assignment, career-lasting or longer peer bonds. ${ }^{80}$ Additionally, Airmen will realize they are not alone in their struggles for love, belonging and esteem. The Game recognizes,

"We all wrestle with a sense of inadequacy. But when we realize that we're not as inadequate as we thought we were, and when we realize everybody else also thinks they are inadequate, then that ache goes away and the idea that we're not a person of value disappears to some extent." ${ }^{81}$ 
Through this shared sense of commonality, Airmen will normalize ${ }^{82}$ realizing their internal struggles are not unique and gaining important skills and knowledge. ${ }^{83}$ Finally, when facilitators encourage target population Airmen with social capital to become PEERs, they also produce model day-to-day advocates within units and the more volatile social scene. ${ }^{84}$

Finally, though this program is a vaccine for sexual assault, the face of the effort will no longer bear the ugly image of sexual assault—a critical factor. Women will not all feel like victims or potential victims and, similarly, men will not feel like they are all rapists or potential rapists; a consistent complaint among Airmen during current prevention efforts, leading to a passive audience. Skills for Life offers non-attribution discussions of numerous sensitive topics, sexual assault being one of many. It behooves the AF to brand this program as an investment in its Airmen to give them tools for a successful life—-providing models of success rather than discussions focused only on what not to do. Further, targeting Maslow's third and fourth level motivations will assist in many other DoD concerns such as divorce, financial debt, "suicide, ${ }^{85}$ drug and alcohol abuse, and other high risk behaviors." ${ }^{86}$ 


\section{Conclusion}

DoD must remember, as it struggles to solve this internal problem, there is a much larger cultural problem beyond its scope-and that culture continues to feed our volunteer-force and is no further adept at finding a vaccine. Sexual assault will continue to plague America until it tackles root problems, possibly a Skills for Life effort via the K-12 education system. The current AF prevention effort, now encompassing intra-unit informational group discussions and connection-messaging to educate its Airmen, is not enough. Civilian and military senior leaders must support a fundamental change in the prevention philosophy ${ }^{87}$ to focus on root causes and special needs of its target population.

Skills for Life incorporates up-to-date prevention concerns, human motivation theory, and readily available assets. All Airmen, but particularly new Airmen, must gain skills to understand and operate within the web of communication, relationships, love, belonging and esteem if the military honestly aspires "to reduce - with the intent to eliminate" ${ }^{\text {"88 }}$ the cancer within its ranks; otherwise, it is an unrealistic goal. Expanding CAF to execute a CCLD sponsored developmental curricula, and a PEER-like program with private-sector training, offers a pioneering vaccine finally aimed at root causes of sexual assault—and other high risk issues of the target population. The Superintendent of USAFA, daily immersed in 4,000 members of the target population, sums it up best:

"Life is coed isn't it? It's a big world out there and we're dealing with very complex issues. We need every aspect of our national strength to really deal with these complex issues. I think in terms of leadership and being well-roundedunderstanding our own motivations and talents and understanding those of others. . it's about the human condition.”89 


\section{Notes}

1. US Senate, Violence Against Women: Global Costs and Consequences: Hearing before the Committee on Foreign Relations. 111th Cong., 1st sess., 2009, 2. Senator John Kerry cites UN and World Bank reports, " 6 out of every 10 women worldwide experience physical or sexual assault and violence in their lifetime. . . and between the ages 16 and 44, rape and domestic violence are more dangerous than cancer, motor vehicle accidents, war and malaria."

2. Quoted in Elizabeth A. Armstrong, Laura Hamilton and Brian Sweeney, "Sexual Assault on Campus: A Multilevel, Integrative Approach to Party Rape.” Social Problems 53, issue 4 (2006): 484.

3. Armstrong et al, "Sexual Assault on Campus," 486.

4. Ibid., 484.

5. HQ SAPRO, "Public Affairs Guidance for Public Release of POTUS Report,” v3, 3 December 2014, 1-2.

6. Department of Defense, United States Air Force Report on Sexual Assault Prevention and Response to the President of the United States, (Washington DC: Secretary of the Air Force, 4 November 2014), 130. The author calculated " 3000 ” based on the RAND estimates that indicate DoD receives one out of every four victims (up from 1 in 10 in 2012) and AF receives one in three (up from 1 in 6 in 2012).

7. http://www.businessballs.com/bloomstaxonomyoflearningdomains.htm, accessed 28 Jan 2015. The difference between "willing to hear and passive participation" versus "adopting a belief system" where the individual is "self-reliant and behaves consistently."

8. Center for Character and Leadership Development (CCLD), "Developing Leaders of Character at the United States Air Force Academy: A Conceptual Framework," (United States Air Force Academy, Colorado Springs, CO, 2011.

9. Department of Defense, “DoD SAPR Prevention Strategy 2014-2016,” (April 2014), http://sapr.mil/public/docs/prevention/DoD_SAPR_Prevention_Strategy_2014-2016.pdf, (accessed 7 December 2014).

10. Department of Defense Instruction (DODI) 6495.02, Sexual Assault Prevention and Response (SAPR) Program Procedures, 28 March 2014, 64.

11. Air Force SAPR Stand-Down Day, “Identifying Offenders," 2014, 3, 5-6.

12. DoD, Report to the POTUS on SAPR, 47.

13. Ibid., 64.

14. CCLD, "Developing Leaders," 12.

15. Quoted in Peter J.S. Lee, “This Man’s Military: Masculine Culture's Role in Sexual Violence.” Research Report. Maxwell AFB, AL: School of Advanced Air and Space Studies, 2014, 6.

16. DoD, Report to the POTUS on SAPR, 60. "Demographic age range of 17-24; the majority of victims and many perpetrators are within this age group. Of the 3,337 Unrestricted Reports of sexual assault in the DoD in FY 2013, 65 percent of the victims and 41 percent of the alleged perpetrators were between the ages of 16 and 24.” Provisional data indicates similar trending for FY 2014. https://www.rainn.org/statistics, accessed 6 Dec 14. Reports statistics showing 80\% victims are under the age of 30.

17. Lee, “This Man's Military,” 32.

18. DODI 6495.02, SAPR, 64. 
19. Sharyn J. Potter and Mary M. Moynihan, "Bringing in the Bystander In-Person Prevention Program to a U.S. Military Instillation: Results From a Pilot Study,” Military Medicine 176, no. 8 (2011), 871.

20. Ibid., 871.

21. Sharyn J. Potter, and Jane G. Stapleton, “Translating Sexual Assault Prevention from a College Campus to a United States Military Instillation: Piloting the Know-Your-Power Bystander Social Marketing Campaign,” Journal of Interpersonal Violence 27, no. 8 (2012), 1616.

22. Air Force Scientific Advisory Board (SAB), "Combating Sexual Assault," Study for Secretary of the Air Force, approved to use in this paper by HQ AF/CVS, 2014, slide 3. An extensive review of literature, professional and academician perspectives, corporate, and government resources including an inspection of three AF bases-interviewing members and reviewing local sexual assault program, procedures and resources. "Reviewing the scientific work done . . .and helping the Air Force use that work to combat the sexual assault problem."

23. Ibid., slide 14 .

24. DoD, Report to the POTUS on SAPR, 16. "The social-ecological model considers the complex interplay between individual, relationship, community, and societal factors, and allows the Department to address those factors that put people at risk for experiencing or perpetrating violence."

25. Lundy Bancroft, Why Does He Do That? Inside the Minds of Angry and Controlling Men (New York, NY: G.P. Putnam’s Sons, 2002), 320.

26. Corey, I Never Knew, 178.

27. Bancroft, Why Does He Do That? 328

28. Famous Footwear: https://www.youtube.com/watch?v=CAf_sfX5dug\&sns=em; Skittles: https://www.youtube.com/watch?v=gOBhJC_oylI

29. Lee, “This Man’s Military,” 72.

30. Martin D. Schwartz, and Walter S. DeKeseredy, Sexual Assault on College Campus: The Role of Male Peer Support, California: SAGE Publications, 1997, 95. "While only a minority of men actually commit sexual assault or battery, the vocabularies and attitudes that give support, permission or approval for such actions are held by a wide variety of people.”

31. Jessica A. Turchik and Susan M. Wilson, "Sexual Assault in the U.S. military: A review of the literature and recommendations for the future," Aggression and Violent Behavior 15 (2010), 270.

32. DoD, Report to the POTUS on SAPR, 49. DoD does recognize the coercion strategy and is now proactive in educating on this topic.

33. Sally K. Ward, Kathy Chapman, Ellen Cohen, Susan White and Kirk Williams, “Acquaintance Rape and the College Social Scene,” Family Relations 40, no.1 (January 1991), 70. "Both sexes have difficulty distinguishing platonic friendliness from sexual invitation."

34. Kristen N. Jozkowski, and Zoe D. Peterson, "Assessing the Validity and Reliability of the Perceptions of the Consent to Sex Scale,” Journal of Sex Research 51, no. 6 (2014), 644. College students admit 3 out of 5 ways of obtaining acceptable consent is nonverbal.

35. Neil Strauss, The Game: Penetrating The Secret Society of Pickup Artists, New York: HarperCollins, 2005, 217-218. Note the technique of "wash-rinse-repeat."

36. Ward et al, “Acquaintance Rape,” 71. 
37. Christine A. Gidycz, Jennifer B. Warkentin, Lindsay M. Orchowski, and Katie M. Edwards, “College Men’s Perceived Likelihood to Perpetrate Sexual Aggression,” Journal of Aggression, Maltreatment and Trauma 20 (2011), 272.

38. Air Force SAPR, “Identifying Offenders,” 14.

39. Sexual assault reports stemming from an end-of-date kiss can be avoided by discussing dating-rituals and developing up-front communication skills prior to the moment.

40. Ward et al, “Acquaintance Rape,” 70.

41. Peter J. Burke, Jan E. Stats and Maureen A. Pirog-Good, "Gender Identity, Self-Esteem, and Physical and Sexual Abuse in Dating Relationships,” Social Psychology Quarterly 51, no. 3 (September, 1988), 275. "Sexual coercion is more likely to be viewed as acceptable by both men and women in more serious relationships."

42. CCLD, "Developing Leaders,” 12.

43. Strauss, The Game, 150.

44. Ibid., 394-395.

45. Ibid., 242.

46. Ibid., 436.

47. Armstrong et al, "Sexual Assault on Campus," 488.

48. http://commons.wikimedia.org/wiki/File:Maslow's_Hierarchy_of_Needs.svg, accessed 11 Nov 2014.

49. SAB, “Combating Sexual Assault," slide 22.

50. Abraham H. Maslow, Motivation and Personality, NY: Harper and Row, 1954, 6.

51. Maslow, Motivation, 58.

52. Ibid., 76.

53. Lee, “This Man’s Military,” 53-54. An important finding is recent evidence that previously victimized females are more likely to choose to join the military. The author would postulate this may be seen as a fresh start, a way to escape from the previous life and reminder of the assault or possibly view the military as a safer environment. However, there is also the counter consideration that victimology would inspire some victims to want to be around more men.

54. Maslow, Motivation, 20.

55. Ibid., 20.

56. Ibid., 21.

57. Ibid., 21.

58. Maslow goes to great lengths to explain his removal of "youngsters” in his study of selfactualized people offered in Chapter 11 of his book, Motivation and Personality. In summary, he states they have not yet achieved identity, or autonomy. Page xxvi lists a lengthy description of the characteristics he ascribes to this population which is undoubtedly the very same reasons and characteristics that attributes the same population of "youngsters" commonly targeted for sexual assault.

59. Bancroft, Why Does He Do That? , 64-65.

60. Diana M. Elliott, Doris S. Mok, and John Briere, “Adult Sexual Assault: Prevalence, Symptomatology, and Sex Differences in the General Population,” Journal of Traumatic Stress v17, no.3 (June 2004), 203-204. A 2004 study of 941 participants, qualifying as a nationally representative sample, found 22\% women and 3.8\% men reported adult sexual assault. Particularly significant to the Air Force is those victims report experiencing negative symptoms 
even after an average of over 14 years since the occurrence of the sexual assault, still citing fear, anxiety, depression, PTS, decreased self-esteem, social difficulties and sexual dysfunction. Assaulted men reported greater symptomatology than women, usually manifested in subsequent behavioral problems, suicidality, violence and substance abuse. The Air Force costs associated with multi-dimensional treatments alone should give incentive to consider a root cause prevention solution.

61. DoD, Quadrennial Defense Review, March 2014, xii. "Eliminating sexual assault is one of the DoD's highest priorities, requiring an absolute and sustained commitment to improving the Department's prevention and response programs."

62. Comprehensive Airman Fitness, "Master Resilience Trainer Course: Student Workbook,” Version 1.6, June, 4. The Air Force Resilience Division stood up in 2010 in response to the CSAF's prioritization of resilience being "one of the top AF readiness issues due to high OPSTEMPO, persistent suicide rates, and self-defeating behaviors.” They created CAF as a new model of fitness incorporating the CJCS Total Force framework to "move beyond the idea of simply having a sound body to a more holistic view of health and fitness that includes both mind and body.” (Wayne B. Jonas, Colonel Francis G. O’Conner, Patricia Deuster, Jonathan Peck, Caron Shake, Stephen S. Frost, "Why Total Force Fitness?” Military Medicine 175, 8:6, 2010, 1) This picture of mental fitness speaks directly to the Skills for Life concept of self-actualization through understanding love, belonging and esteem. However, the current CAF curriculum of 12 points (CAF Branch, “CAF Overview,” 29 Aug 2014, slide 6) focuses mostly on mental resiliency and coping with life stressors-preparing for an optimal reaction and recovery from a traumatic event — rather than building skills in order to avoid the events. (Note: The author acknowledges the resiliency program is crucial as there are many unavoidable traumatic events that occur in life. Nor is she implying that all sexual assaults are avoidable. There is no intent to disparage or take away from the resiliency curriculum, merely to add to make a more robust program to account for both sides of life events, pre and post).

63. Several thoughts on why small groups should not be constructed within the day-to-day unit. First, fear to share sexual assault information with a unit member who may feel compelled to report to SARC or chain. Secondly, no one wants to share sensitive emotional issues to a room of people you will see in the hallways at work every day-especially the target population. Lastly, the study embedded in a female college dorm showed how homogeneity further intensifies social anxiety (Armstrong, "Sexual Assault on Campus," 489). These all indicate the need for small groups to not be constructed within the homogeneity of the day-to-day unit. Additionally, a recent article acknowledges "people avoid confiding in others because, inevitably, word gets around to someone else” Craig Lambert, "Choosing Confidants," http://harvardmagazine.com/r/?47336, Jan-Feb 2015; accessed 27 December 2014. All of these considerations show a unit mandate makes building trusted networks extremely difficult.

64. CCLD, “Developing Leaders,” 14-15.

65. Interview with Lieutenant Colonel David F. Swayne Jr., Director of Peak Performance Center, USAFA, 21 October 2014. Additionally, The American Group Psychotherapy Association, "Practice Guidelines for Group Psychotherapy: Science to Service Task Force,” 2007, 10. http://www.agpa.org/docs/default-source/practice-resources/download-full-guidelines(pdf-format)-group-works!-evidence-on-the-effectiveness-of-group-therapy.pdf?sfvrsn=2, accessed 27 December 2014. 
66. AF SAPR Office, “2015 Annual SAPR Training,” Talking Paper, Pentagon, Washington D.C., 10 December 2014.

67. CCLD, “Developing Leaders,” 18. And can also enhance various levels of trust: trust in self, those in supervisory roles, and the organization (Ibid., 19).

68. The author self-selected a small team of USAFA air officer commanders, seasoned academic instructors, athletic coaches, and counselors in Oct 2013-incorporating at least one member from each mission element directly engaged with daily USAFA cadet life. Important to note cadets within the PEER program supported this initial concept.

69. Corey, I Never Knew, vii-viii.

70. The CCLD stood up in 2011, supporting USAFA's mission to transform cadets and the AF's future officers into leaders of character. The underlying reason for the Center's creation recognizes the complex challenge of transforming a diverse group of 4000 young men and women with differing cultural and familial experiences, values and beliefs; ultimately embodying the AF Core Values and USAFA Honor Code by the end of their 4-year experience. The CCLD's theory-supported, evidence-based framework assists the multi-faceted organization to "inspiring cadets to live honorably. . .lift others into their best possible selves and . . .elevate performance toward a common and noble purpose” (CCLD, "Developing Leaders," 4). The Academy's development mission, encapsulated in 9 principles, aspires to cadet self-efficacy and engraining identity-conferring behaviors into firm and stable habits (Ibid., 14-15).

71. The first tier incorporates both CAF accession resiliency goals and critical initial Skills for Life concepts to lay the foundation prior to a first assignment. For example, frank conversations about the basic biology of sex, safe sex, STDs, sexual harassment \& assault needs to come quickly in the program to ensure normalization. Same-sex groups are needed in initial tiers, to establish a peer support network, wingman concept and most importantly, a forum to expose similar life fears and struggles. As Chief Master Sergeant of the AF Cody states, "When you face significant challenges. . .you're not alone” (Desktop Operating Guide for CAF, Oct 2014, 5). Removing aloneness is key to CAF and Skills for Life and why careful topic prioritization and timing is crucial. The 2nd tier aims on ground-laying topics of love, acceptance, male vs. female communication and relationships-prior to the lifestyle and freedom experienced following accession, or BCT in the case of USAFA/ROTC. Consider integrating sexes during 3nd tier topics in technical training assignments. Airmen must learn to discuss difficult topics with both men and women; further expanding the peer network, appreciating male and female perspectives and enhancing supervisor/subordinate communication beyond the program. 4th tier, first-assignment phase, incorporates local squadrons, missions and demographics issues via a Community Support Coordinator's (CSC) ${ }^{74}$ execution plan. Lastly, the 5th tier will expand to appreciate multi-generation perspectives while reinforcing concepts and creating new networks throughout an Airman's career.

72. Currently, the Air Force has 1,012 Military Resilience Trainers (MRT), with a funded plan to expand to 1 MRT per 200 Airmen or per squadron, a goal of 2700-3000 by 2016 (18 Aug 2014, CAF Communication Plan, 1-2). The already funded budget and manpower is a significant first step, making Skills for Life more palatable in the current fiscal climate. Additional manpower/funds needed to fully target officer/enlisted accession, technical training and larger first-assignment communities. CAF already intends to incorporate these arenas, thus, funding for full-time MRTs assigned to these bases will allow Skills for Life small group sessions and tracking of the largest concentration of the target population. Finally, the current CAF 
facilitator style is very hands-on with active group exercises embedded within the curriculum. Although some of the resiliency lessons appear still too academic focused for Skills for Life, the expected delivery incorporates the atmosphere needed to approach the open dialogue intended for the new curriculum. Noted, some of the proposed Skills for Life topics, such as loneliness and depression, are already in the CAF curriculum; coordination, intermingling, and possibly even eventual combining of these programs will be necessary since resiliency is a subset of the self-autonomous goal of Skills for Life.

73. MRT is an additional duty where candidates volunteer, but also must be recommended by their leadership,. They attend a 2-week immersion to prepare them for their duties. The vision is to foster resilience in four domains: mental, physical, social, and spiritual. As an additional duty, an MRT along with selected unit Resiliency Trainer Assistants, acts as a facilitator for selected monthly training directed by the Community Support Coordinator, including Wingman Days, as well as a known access point within a squadron to provide advice and recommendations on resources available. The AFI requires Airmen accomplish a minimum of 4 hours of resiliency training per year, currently tracked via ADLS. Most importantly, in line with the Skills for Life concept, permission from the AF learning council recently approved the CAF to build curriculum for all AF accession schools and programs. Additionally, there will be more targeted intervention in First Term Airman Centers (FTAC) and Professional Military Education (PME). Finally, this program continues to explore new ways to serve their Airmen....an iOS and Android application, CAF Wingman Tool, went live in Dec 2014 providing an online self-assessment tool. Interview with Lieutenant Colonel Todd R. Alcott, Resiliency Program Manager, CAF Branch, 21 November 2014. Additionally, CAF, “Master Resilience Trainer Course,” 6.

74. The CSC serves as the Community Action Information Board Exec/Integrated Delivery System Chair and manages resilience initiatives such as the Master Resilience Trainers (MRT), Leadership Pathways, and Wingman Day or resilience events for MAJCOM/Wing Commander (HQ/A1SAY, "CAF Communication Plan,” 9).

75. A global institution most commonly recognized is The Landmark Forum, advertising a program designed to build effectiveness and power in "the quality of your relationships, your personal productivity, the difference you're out to make, [and] the degree to which you enjoy your life” (http://www.landmarkworldwide.com/the-landmark-forum accessed on 9 Nov 2014). There are also smaller companies offering similar experiences in local areas where some military men and women have attended, as well as assisting some military organizations with consultation. Prominent national corporations and small business owners invest in their employees to attend forums "to build more effective teams with tools for effective communication to inspire and promote action” (https://pathwaysseminars.com/ accessed on 9 Nov 2014).

76. https://pathwaysseminars.com/ accessed on 9 Nov 2014. Pathways, founded in 1984, utilizes individual, small group and large group exercises for the realization of how self-values and history effects handling personal and professional relationships. "The success of any team lies within its players. . . [where] each member needs to review their approach and effectiveness and uncover what current beliefs and behaviors they currently operate from.” The fundamental process in building effective teams rests on the personal development of each individual in areas of personal leadership, giving and receiving feedback, being accountable and holding others accountable, making and keeping agreements, handling conflict, taking risks and encouraging creativity - the very concept of Skills for Life. 
77. The Air Force cannot afford to send every Airmen to forums such as these; however, MRTs, RTAs/PEERs would benefit immensely in execution of their CAF duties. A resource like Pathways can offer new exercise techniques, group facilitation concepts, consultation or trainthe-trainer opportunities. For example, Pathways is creating a unit-tailored program for an Army Guard unit, encompassing issues identified by its leadership while also allowing for independent self-actualization - inline with another SAB recommendation for a locally tailored SAPR program. Their preliminary pilot program utilizes computer-based training to introduce tools and terms, group/individual experiential exercises and facilitated discussions.

78. Each USAFA squadron has 1-2 peer support-providers, usually junior or senior cadets. Though not technically a counselor, PEER cadets are treated in this regard, where fellow cadets come to them with personal struggles in a non-attribution setting. There are a wide-range of issues discussed, from time-management or failing a class to boy-friend/girlfriend/parent/roommate relationship problems to suicidal ideation or sexual assault. These PEERs provide "education, outreach, someone to listen and someone who can refer the cadet to the appropriate helping agency for further support" (Peak Performance Center, "Personal Ethics and Education Representatives,” Talking Paper, United States Air Force Academy, CO, 1 August 2014). These members are an important element to the squadron providing a soundingboard for ways to approach more simple daily struggles and support to approach the commandchain or other agencies (SARC, Mental Health, etc) when it is a bigger issue. Furthermore, PEERs provide squadron-members additional choices within the squadron when dealing with life issues - one issue may be more approachable with one person than another. The SAB findings highlight "first-line supervisors are most crucial to sexual assault prevention but lack sufficient education to set and maintain unit culture, confront inappropriate behavior, foster risk management in troops” (SAB, “Combating Sexual Assault,” slide 14). This is an important finding but operationally problematic for the training level required due to sheer quantity and constant changes in supervisors. (Note: The author concurs with SAB recommendation to remove the "mandatory reporting” status of a supervisor. The current policy makes it difficult for a victim to discuss concerning issues with their supervisors and hurts the mentor-mentee portion of the relationship. Furthermore, it makes a sexual assault situation worse by a supervisor's focus on whether they are required to report, or pushing a supervisee out of the office before they reveal something that is mandatory to report...rather than simply focusing on getting the supervisee the help they need regardless of circumstance).

79. Lee, “This Man’s Military,” 72. The supervisor first-line of defense is afflicted by a "generational-divide” (Lee, “This Man’s Military,” 39). Setting up unit PEERs bolsters the CAF's RTA concept and provides a resource to assist commanders when supervisors may not be approachable-not only in receiving sanitized feedback on trending issues, but also in creating tailored unit or mission specific Skills for Life modules. Finally, MRTs and RTAs can preidentify possible PEER candidates with social capital to be enveloped in the program and possibly groomed as future MRTs. It is essential to identify natural leaders who mentor their peer group, incorporating SAB's and Maj Lee's recommendations for peer leadership, directly in-line with CCLD and PEER concepts: “Today's followers are tomorrow's leaders, and for this reason, it may be useful to shape promotion systems (especially in the 18-24 year old demographic) to one that rewards peer leadership instead of classically described followership” (Ibid., 72). 
80. The design of small groups to build trust over time and sharing of current life experiences allows for "developmental coaching” (CCLD, "Developing Leaders," 21) in a safe environment while also building peer support relationships. "Too often, events pass without any internal alarm being sounded that 'this moment matters,' indicating the need for intentional consideration or engagement....[and] reflect assumptions, biases and inaccuracies that limits one's reasoning” (Ibid., 25). Skills for Life will reorient people's understanding of relationships and communication, making them aware of their own assumptions and biases while developing habits to consider others' perspectives—sometimes recognizing the importance of making an uncomfortable decision.

81. Strauss, The Game, 430-431.

82. Normalizing new Airmen, coming from different geographical, cultural and familial experiences, on basic information like sex, STDs, and definitions will allow a more equitably educated population. Similar to the Air Force's attempt to normalize officer accession experiences via the Air and Space Basic Course (ASBC).

83. For example, it was surprising to USAFA's Vice Commandant of Culture and Climate on how many USAFA cadets did not know the basic biology of sex.

84. The very core of AF bystander training speaks to the difficulties for individuals to make a decision that may put them in an uncomfortable position with friends or peers, termed by CCLD as the decision-action gap (CCLD, "Developing Leaders," 27). Skills for Life intends to break those barriers early in an Airman's career and not just for the sexual assault arena. Finally, CCLD aspires to create a "culture where the principles of development are constantly present ...to not only develop Leaders of Character, but to produce those who develop other Leaders of Character-developers of developers" (Ibid., 29). Similarly, the AF-wide solution needs to harness these concepts. CAF has the initial cadre concept, but needs peer-level networks furthering the principals, demonstrating, or assisting others during life events. The ideal endstate is where Airmen own their roles in convincing peers about the value of these life skills (Ibid., 31).

85. Interview with Lieutenant Colonel Kathleen A. Crimmins, Headquarters AF Suicide Prevention Program Manager, 12 December 2014. The most consistently related factor for military suicide, approximately two-thirds to three-fourths of cases, is some form of relationship problem. Learning successful negotiation within a relationship to include relationship closure would assist in suicide prevention.

86. DoD, 18th Chairman's 2nd Term Strategic Direction to the Joint Force, Washington DC: Chairman of the Joint Chiefs of Staff, 2013, 9.

87. Note the FY13-17 spending cuts in most sexual assault earmarks in the Violence Against Women Reauthorization Act 2012 (STOP grants, SASP, rape prevention education grant, etc)...what kind of message is Congress sending despite the rhetoric of sexual assault being their highest concern in the military? (US Senate, Violence Against Women Reauthorization Act of 2012, 112th Cong., 2nd sess., H.R. 4970, Report together with Dissenting Views., 112, no. 480, part 1, 15 May 2012, 79-85) Though the proposed Skills for Life sounds expensive, further analysis would show current sexual assault rates purport much worse costs to the military in victim long-term care and legal costs for prosecution.

88. DoD, Report to the POTUS on SAPR, 21. 
89. Lieutenant General Michelle Johnson, National Public Radio interview conducted by Michel Martin, http://www.npr.org/2014/03/25/294241138/air-force-academys-first-womanchief-takes-on-sexual-assault, 25 March 2014. 


\section{Bibliography}

Air Force SAPR Stand-Down Day. “Identifying Offenders.” Concept of operations.

Washington DC: Headquarters Air Force SAPRO, 2014.

Air Force Scientific Advisory Board. “Combating Sexual Assault.” Study for Secretary of the Air Force, approved to use in this paper by HQ AF/CVS, 2014.

Armstrong, Elizabeth A., Laura Hamilton and Brian Sweeney. "Sexual Assault on Campus: A Multilevel, Integrative Approach to Party Rape.” Social Problems 53, issue 4 (2006): 483-499.

Bachar, Karen and Mary P. Koss. Sourcebook on Violence Against Women: Chapter 7, From Prevalence to Prevention California: Sage Publications, Inc., 2001.

Bancroft, Lundy. Why Does He Do That? Inside the Minds of Angry and Controlling Men. New York, NY: G.P. Putnam’s Sons, 2002.

Bell, Margaret E., and Annemarie Reardon. "Experiences of Sexual Harrassment and Sexual Assault in the Military Among OEF/OIF Veterans: Implications for Health Care Providers.” Social Work in Health Care 50, no. 1 (2011): 34-50.

Burke, Peter J., Jan E. Stats and Maureen A. Pirog-Good. "Gender Identity, Self-Esteem, and Physical and Sexual Abuse in Dating Relationships.” Social Psychology Quarterly 51, no. 3 (September, 1988): 272-285.

Castro, Carl Andrew, and Amy B. Adler. Resilience and Mental Health: Challenge Across the Lifespan. New York, NY: Cambridge University Press, 2011.

Center for Character and Leadership Development (CCLD). "Developing Leaders of Character at the United States Air Force Academy: A Conceptual Framework." United States Air Force Academy, Colorado Springs, CO, 2011.

Comprehensive Airman Fitness (CAF) Branch, “CAF Overview,” 29 Aug 2014.

Comprehensive Airman Fitness Branch, "Master Resilience Trainer (MRT) Course: Student Workbook,” Version 1.6, June, 6.

Corey, Gerald. I Never Knew I Had A Choice. Monterey, CA: Brooks/Cole Publishing, 1983.

Department of Defense. $18^{\text {th }}$ Chairman's $2^{\text {nd }}$ Term Strategic Direction to the Joint Force.

Washington DC: Chairman of the Joint Chiefs of Staff, 2013.

Department of Defense. “DoD SAPR Prevention Strategy 2014-2016.” April 2014.

http://sapr.mil/public/docs/prevention/DoD_SAPR_Prevention_Strategy_2014-2016.pdf,

(accessed 7 December 2014).

Department of Defense, Quadrennial Defense Review, March 2014.

Department of Defense. Report to the President of the United States on Sexual Assault

Prevention and Response. Washington DC: Secretary of Defense, 25 November 2014.

Department of Defense. United States Air Force Report on Sexual Assault Prevention and Response to the President of the United States. Washington DC: Secretary of the Air Force, 4 November 2014.

Department of Defense Instruction (DODI) 6495.02. Sexual Assault Prevention and Response (SAPR) Program Procedures. 28 March 2014.

Elliott, Diana M., Doris S. Mok, and John Briere, “Adult Sexual Assault: Prevalence, Symptomatology, and Sex Differences in the General Population,” Journal of Traumatic Stress v17, no.3 (June 2004), 203-211.

Gidycz, Christine A., Jennifer B. Warkentin, Lindsay M. Orchowski, and Katie M. Edwards. “College Men’s Perceived Likelihood to Perpetrate Sexual Aggression.” Journal of 
Aggression, Maltreatment and Trauma 20 (2011): 260-279.

Headquarters Air Force Sexual Assault Prevention Response Office, "2015 Annual SAPR

Training,” Talking Paper, Pentagon, Washington D.C., 10 December 2014.

Headquarters Air Force Sexual Assault Prevention Response Office. "Public Affairs Guidance:

Public Release of 2014 POTUS Report.” Version 3, 3 December 2014.

Jonas, Wayne B., Colonel Francis G. O’Conner, Patricia Deuster, Jonathan Peck, Caron Shake,

Stephen S. Frost. “Why Total Force Fitness?” Military Medicine 175, 8:6 (2010): 1.

Jozkowski, Kristen N., and Zoe D. Peterson. "Assessing the Validity and Reliability of the

Perceptions of the Consent to Sex Scale.” Journal of Sex Research 51, no. 6 (2014): 632645.

Katz, Lori S., Geta Cojucar, Sayeh Beheshti, Erin Nakamura, and Michelle Murray. "Military

Sexual Trauma During Deployment to Iraq and Afghanistan: Prevalence, Readjustment

and Gender Differences.” Violence and Victims 27, no. 4 (Nov, 2012): 487-499.

Lapp, Kathleen G., Hayden B. Bosworth, Jennifer L. Strauss, Karen M. Stechuchak, Ron D.

Horner, Patrick S. Calhoun, Keith G. Meador, Steven Lipper, and Marian I. Butterfield.

"Lifetime Sexual and Physical Victimization among Male Veterans with Combat-Related

Post-Traumatic Stress Disorder.” Military Medicine 170, no. 9 (2005): 787-790.

LeardMann, Cynthia A., Amanda Pietrucha, Kathryn M. Magruder, Besa Smith, Maureen

Murdoch, Isabel G. Jacobson, Margaret A.K. Ryan, Gary Gackstetter, Tyler C. Smith.

"Combat Deployment Is Associated with Sexual Harassment or Sexual Assault in a Large,

Female Military Cohort.” Women's Health Issues 23, no. 4 (2013): 215-223.

Lee, Peter J.S., “This Man's Military: Masculine Culture’s Role in Sexual Violence.” Research

Report. Maxwell AFB, AL: School of Advanced Air and Space Studies, 2014.

Lisak, David and Paul M. Miller. "Repeat Rape and Multiple Offending Among Undetected

Rapists.” Violence and Victims 17, no. 1 (2012): 73-84.

Maslow, Abraham H. Motivation and Personality. NY: Harper and Row, 1954.

Maslow, Abraham H. The Farther Reaches of Human Nature. New York: Viking Press, 1971.

Mattocks, Kristin M., Sally G. Haskell, Erin E. Krebs, Amy C. Justice, Elizabeth M. Yano, and

Cynthia Brandt. "Women at war: Understanding how women veterans cope with combat and military sexual trauma." Social Science and Medicine 74 (2013): 537-545.

Munch, Anne. "Sexual Assault: Naming the Unnamed Conspirator (․)" Report for Anne Munch Consulting, Inc.

Peak Performance Center. "Personal Ethics and Education Representatives (PEERS).” Talking Paper. United States Air Force Academy, CO, 1 August 2014.

Potter, Sharyn J., and Mary M. Moynihan. "Bringing in the Bystander In-Person Prevention

Program to a U.S. Military Instillation: Results From a Pilot Study.” Military Medicine 176, no. 8 (2011): 870-875.

Potter, Sharyn J., and Jane G. Stapleton. “Translating Sexual Assault Prevention from a College Campus to a United States Military Instillation: Piloting the Know-Your-Power Bystander Socail Marketing Campaign.” Journal of Interpersonal Violence 27, no. 8 (2012): 1593-1621.

Strauss, Neil. The Game: Penetrating The Secret Society of Pickup Artists. New York: HarperCollins, 2005.

Schwartz, Martin D., Walter S. DeKeseredy. Sexual Assault on College Campus: The Role of Male Peer Support. California: SAGE Publications, 1997.

Turchik, Jessica A., and Susan M. Wilson. "Sexual Assault in the U.S. military: A review of 
the literature and recommendations for the future.” Aggression and Violent Behavior 15 (2010): 267-277.

US Senate. Violence Against Women: Global Costs and Consequences: Hearing before the Committee on Foreign Relations. $111^{\text {th }}$ Cong., $1^{\text {st }}$ sess., 2009.

US Senate. Violence Against Women: Hearing before a Subcommittee of the Committee on Appropriations. $104^{\text {th }}$ Cong., $1^{\text {st }}$ sess., 1996.

US Senate. Violence Against Women Reauthorization Act of 2012. $112^{\text {th }}$ Cong., $2^{\text {nd }}$ sess., H.R. 4970. Report together with Dissenting Views. 112, no. 480, part 1. (15 May 2012).

Ward, Sally K., Kathy Chapman, Ellen Cohen, Susan White and Kirk Williams. "Acquaintance Rape and the College Social Scene.” Family Relations 40, no.1 (January 1991): 65-71 